Article

\title{
In Vitro Cytoprotective Effects and Antioxidant Capacity of Phenolic Compounds from the Leaves of Swietenia macrophylla
}

Sônia Pamplona ${ }^{1, \dagger}$, Paulo Sá ${ }^{1, \dagger}$, Dielly Lopes ${ }^{2, \dagger}$, Edmar Costa ${ }^{2, \dagger}$, Elizabeth Yamada ${ }^{2, \dagger}$, Consuelo e Silva ${ }^{1, \dagger}$, Mara Arruda ${ }^{1, \dagger}$, Jesus Souza ${ }^{3, \dagger}$ and Milton da Silva ${ }^{1, \dagger, *}$

1 Programa de Pós-Graduação em Química, Instituto de Ciências Exatas e Naturais, Campus Universitário do Guamá, Universidade Federal do Pará, Belém-PA 66075-970, Brazil; E-Mails: sgpamplona@yahoo.com.br (S.P.); paulorcsa@gmail.com (P.S.); yumikoyoshioka@yahoo.com.br (C.S.); msparruda@gmail.com (M.A.)

2 Laboratório de Neuropatologia Experimental (LaNEx), Hospital Universitário Barros Barreto, Rua dos Mundurucus, 4487-Guamá. CEP 66073-000. Belém, PA, Brazil;

E-Mails: dicatrina@gmail.com (D.L.); etcosta@globo.com (E.C.); esyamada2013@gmail.com (E.Y.)

3 Faculdade de Engenharia de Alimentos, Instituto de Tecnologia, Campus Universitário do Guamá, Universidade Federal do Pará, Belém-PA 66075-970, Brazil; E-Mail: jesussouza@yahoo.com.br

$\dagger$ These authors contributed equally to this work.

* Author to whom correspondence should be addressed; E-Mail: yumilton@yahoo.com.br; Tel.: +55-91-3201-7365; Fax: +55-91-3201-7635.

Academic Editor: Peter Koulen

Received: 16 July 2015 / Accepted: 25 August 2015 / Published: 16 October 2015

Abstract: Swietenia macrophylla (mahogany) is a highly valued timber species, whereas the leaves are considered to be waste product. A total of 27 phenolic compounds were identified in aqueous extracts from mahogany leaves by comparing retention times and mass spectra data with those of authentic standards using LC-ESI-MS/MS. Polyphenols play an important role in plants as defense mechanisms against pests and pathogens and have potent antioxidant properties. In terms of health applications, interest has increased considerably in naturally occurring antioxidant sources, since they can retard the progress of many important neurodegenerative diseases such as Alzheimer's and Parkinson's diseases. The antioxidant capacities of two aqueous extracts, M1 (decoction) and M2 (infusion), were measured using TEAC and Folin-Ciocalteau methods. Additionally, M1 was used in order to investigate its potential cytoprotective effects on an in vitro model of neurodegeneration, by using primary 
cerebellar cultures exposed to methyl mercury $(\mathrm{MeHg})$. Under experimental sub-chronic conditions (72 h), concomitant exposure of the same cultures to MeHg and M1 extract resulted in a statistically significant increase in cell viability in all three concentrations tested (10,50 and $100 \mu \mathrm{g} / \mathrm{mL}$ ), strongly suggesting that due to its high content of antioxidant compounds, the M1 extract provides significant cytoprotection against the MeHg-induced in vitro neurotoxicity.

Keywords: Swietenia macrophylla; cytoprotection; antioxidant capacity; polyphenols; LC-MS/MS

\section{Introduction}

Serious pathologies such as cancer, senescence and inflammation, harm the membranes of biological systems causing overproduction of radical reactive species and leading to lipid peroxidation [1]. Although free radicals are known to play a physiological role in optimal cell function, excessive oxidative stress has been implicated in a variety of neurodegenerative diseases, including Alzheimer's disease, Parkinson's disease and amyotrophic lateral sclerosis [2]. Oxidative stress also plays an important role in other degenerative conditions such as autoimmune and inflammatory diseases (i.e., ischemia and rheumatoid arthritis), cancer, diabetes mellitus, and atherosclerosis [3], as well as in metal-induced toxicity [4]. It has been suggested that polyphenolic content has a relationship with free radical-scavenging ability, and it has thus received increasing attention over the last decade, especially due to its potential protective effects against degenerative diseases linked to oxidative stress $[5,6]$.

Swietenia macrophylla, commonly known as mahogany, belongs to the Meliaceae family and is distributed naturally from southern Mexico throughout Central and Tropical South America to Bolivia and Brazil, including large portions of the Amazon Basin [7,8]. It is one of the most valuable plants on the international market and because of its beauty and durability its wood is used to make products such as fine furniture and cabinetry, interior trim, paneling, fancy veneers, musical instruments, boat building, pattern making, turnery and carving [9].

Some studies have been reported in the literature about mahogany leaves, bark and seeds providing limonoids [10-12] and their derivatives. In a previous paper, we described the isolation and structural elucidation of six phragmalin-type limonoids from the hexane extract from the leaves of S. macrophylla [10]. Additionally, polyphenolic compounds such as flavonoids have been isolated from Swietenia macrophylla [9].

Falah et al. [9] reported potent antioxidant activity related to catechin and epicatechin isolated from S. macrophylla bark therefore, the study of $S$. macrophylla leaves, potentially rich in polyphenols, may lead to the discovery of new, useful antioxidant sources, providing an incentive for utilization of waste material from the timber industry and above all, the preservation of these plants.

HPLC coupled with an UV-Vis diode array detector (DAD) has been a method of choice for separating and isolating polyphenols $[13,14]$. However, identification of compounds from the patterns can be done safely using LC-HRESITOF-MS analysis.

Several methods can be used to measure the antioxidant capacity of plant extracts. Among these, the Trolox Equivalent Antioxidant Capacity (TEAC) assay and Folin-Ciocalteu assay are considered as reference methods [14]. The TEAC assay measures antioxidant inhibition based on the use of the relatively 
long-lived $\mathrm{ABTS}^{*+}$ by hydrogen atom transfer and thus reflects the classical radical chain breaking antioxidant activity $[14,15]$. The Folin-Ciocalteu assay, which is widely used to quantify the total phenolic content, can be considered as another antioxidant method since the mechanism involved is an electron transfer aiming at neutralizing an oxidant species [16].

Seeking to come up with an analytical method suitable for analyzing polyphenolic compounds in small concentrations in complex mixtures such as aqueous leaf extract, we have developed a LC-HRESITOF-MS procedure which is described herein. This method has proved to be feasible for the analysis of leaf infusions (aqueous extracts, popularly known as "tea"), and has also been applied to mahogany samples in order to illustrate the potential of this method for identification analyses.

LC-MS/MS analyses were also performed to confirm the presence of flavonoids and phenolic acids in aqueous extracts from leaves of S. macrophylla. The LC-MS/MS system is considered one of the most prominent methods in drug development using medicinal plants [17,18].

The aim of this work was to evaluate and compare the antioxidant activity of two aqueous extracts of S. macrophylla leaves - M1 prepared by decoction and M2 by infusion - as well as to identify some of their major polyphenolic compounds by using both the TEAC and the Folin-Ciocalteu assays. Additionally, in the context of the occurrence of oxidative stress in several conditions affecting the nervous system, we used one of these extracts (M1) in order to investigate its potential cytoprotective effects on an in vitro model of neurodegeneration, by using cerebellar primary cultures exposed to methyl mercury (MeHg), a neurotoxicant known to cause oxidative stress both in humans and in experimental models.

\section{Results and Discussion}

\subsection{Antioxidant Assays-Trolox Equivalent Antioxidant Capacity (TEAC) and Folin-Ciocalteu Assays}

The antioxidant capacities presented by two aqueous extracts of $S$. macrophylla are shown in Table 1. The values presented for both methods presented no significant differences between the forms of preparation of extracts $(p<0.05)$, which agrees with Almajano et al. [19] who evaluated the antioxidant capacity of different infusions of teas. The antioxidant capacity presented by the two methods shows that the leaf extract of $S$. macrophylla is an important antioxidant compound source when compared with other Amazonian plant leaf extracts [15].

Table 1. Folin-Ciocalteu (FC) and TEAC values of two aqueous extracts (M1 and M2) of S. macrophylla leaves. Values are expressed as Gallic acid equivalent (GAE) or mmol of Trolox equivalent (TE) both per g of dry crude extract (DCE).

\begin{tabular}{ccc}
\hline \multirow{2}{*}{ Extracts } & $\begin{array}{c}\text { TP } \\
\text { mg GAE per g DCE }\end{array}$ & $\begin{array}{c}\text { TEAC } \\
\text { mmol TE per g DCE }\end{array}$ \\
\hline M1 & $228.10 \pm 2.40$ & $2.43 \pm 0.06$ \\
M2 & $245.15 \pm 9.69$ & $2.11 \pm 0.14$ \\
\hline
\end{tabular}

\subsection{Identification of Phenolic Compounds in Aqueous Extract of S. Macrophylla Leaves}

The M1 extract was eluted by gradient mode and the total ion current (TIC) chromatogram (Figure 1) was acquired by UPLC-TOF/MS, in which 27 phenolic compounds including phenolic acids and flavonoids have 
been identified. The mass spectrum of these compounds was obtained in positive ion mode by a $\mathrm{MS}^{\mathrm{e}}$ experiment. This experiment makes it possible to observe in a single analysis both the molecular ion and the fragmentation of each identified component. The identification of polyphenols from M1 extract was carried out by comparing retention times and mass spectra with those of commercial standards using their respective $m / z$ ratios.

The M1 extract showed a similar chromatographic profile when compared with standard compounds, whose peaks have been assigned in Table 2. All the standard compounds were detected and confirmed in the M1 extract.

Table 2. Phenolic compounds with their respective retention times and $\mathrm{m} / \mathrm{z}$ ratio identified in the M1 extract.

\begin{tabular}{|c|c|c|c|c|c|}
\hline Compounds & $\begin{array}{c}\text { Empirical } \\
\text { Formula }\end{array}$ & $\begin{array}{c}\text { RT } \\
(\min )\end{array}$ & $\begin{array}{c}{[\mathbf{M}+\mathbf{H}]^{+}} \\
\text {Calcd } \\
\end{array}$ & $\begin{array}{c}{[\mathbf{M}+\mathbf{H}]^{+}} \\
\text {obsd }\end{array}$ & $\begin{array}{l}\text { Error } \\
(\mathrm{ppm})\end{array}$ \\
\hline Benzoic acid & $\mathrm{C}_{7} \mathrm{H}_{5} \mathrm{O}_{2}$ & 0.41 & 123.0446 & 123.0446 & 0.00 \\
\hline$p$-Hydroxybenzoic acid & $\mathrm{C}_{7} \mathrm{H}_{6} \mathrm{O}_{3}$ & 1.73 & 139.0395 & 139.0390 & 3.59 \\
\hline Cinnamic acid & $\mathrm{C}_{9} \mathrm{H}_{8} \mathrm{O}_{2}$ & 3.36 & 149.0602 & 149.0600 & 1.34 \\
\hline Gentisic acid & $\mathrm{C}_{7} \mathrm{H}_{6} \mathrm{O}_{4}$ & 1.26 & 155.0344 & 155.0343 & 1.29 \\
\hline Protocatechuic acid & $\mathrm{C}_{7} \mathrm{H}_{6} \mathrm{O}_{4}$ & 1.28 & 155.0344 & 155.0342 & 1.29 \\
\hline Synaptic acid & $\mathrm{C}_{9} \mathrm{H}_{8} \mathrm{O}_{3}$ & 2.22 & 165.0551 & 165.0548 & 1.81 \\
\hline$p$-Coumaric acid & $\mathrm{C}_{9} \mathrm{H}_{7} \mathrm{O}_{3}$ & 2.23 & 165.0551 & 165.0548 & 1.81 \\
\hline Gallic acid & $\mathrm{C}_{7} \mathrm{H}_{5} \mathrm{O}_{5}$ & 0.81 & 171.0293 & 171.0291 & 1.16 \\
\hline Syringic acid & $\mathrm{C}_{9} \mathrm{H}_{9} \mathrm{O}_{5}$ & 2.90 & 199.0606 & 199.0607 & 0.50 \\
\hline Resveratrol & $\mathrm{C}_{14} \mathrm{H}_{12} \mathrm{O}_{3}$ & 3.99 & 229.0864 & 229.0864 & 0.00 \\
\hline Chrysin & $\mathrm{C}_{15} \mathrm{H}_{10} \mathrm{O}_{5}$ & 1.16 & 271.0606 & 271.0611 & 1.84 \\
\hline Apigenin & $\mathrm{C}_{15} \mathrm{H}_{9} \mathrm{O}_{5}$ & 3.78 & 273.0762 & 273.0765 & 1.09 \\
\hline Naringenin & $\mathrm{C}_{15} \mathrm{H}_{12} \mathrm{O}_{5}$ & 3.88 & 273.0762 & 273.0766 & 1.46 \\
\hline Luteolin & $\mathrm{C}_{15} \mathrm{H}_{9} \mathrm{O}_{6}$ & 4.38 & 287.0555 & 287.0555 & 0.00 \\
\hline Kaempferol & $\mathrm{C}_{15} \mathrm{H}_{10} \mathrm{O}_{6}$ & 3.98 & 287.0555 & 287.0554 & 0.34 \\
\hline Epicatechin & $\mathrm{C}_{15} \mathrm{H}_{14} \mathrm{O}_{6}$ & 2.23 & 291.0868 & 291.0873 & 1.71 \\
\hline Catechin & $\mathrm{C}_{15} \mathrm{H}_{14} \mathrm{O}_{6}$ & 2.83 & 291.0868 & 291.0868 & 0.00 \\
\hline Quercetin & $\mathrm{C}_{15} \mathrm{H}_{9} \mathrm{O}_{7}$ & 3.76 & 303.0504 & 303.0506 & 0.66 \\
\hline Epigallocatechin & $\mathrm{C}_{15} \mathrm{H}_{14} \mathrm{O}_{7}$ & 1.07 & 307.0817 & 307.0824 & 2.27 \\
\hline Gallocatechin & $\mathrm{C}_{15} \mathrm{H}_{13} \mathrm{O}_{7}$ & 1.16 & 307.0817 & 307.0823 & 1.95 \\
\hline Myricetin & $\mathrm{C}_{15} \mathrm{H}_{10} \mathrm{O}_{8}$ & 2.38 & 319.0822 & 319.0822 & 0.00 \\
\hline Apigenin-7-O-glucoside & $\mathrm{C}_{21} \mathrm{H}_{21} \mathrm{O}_{10}$ & 3.84 & 435.1291 & 435.1289 & 0.45 \\
\hline Kaempferol-3-O-glucoside & $\mathrm{C}_{21} \mathrm{H}_{20} \mathrm{O}_{11}$ & 4.06 & 449.1083 & 449.1077 & 1.33 \\
\hline Quercetin-3-O-rhaminoside & $\mathrm{C}_{21} \mathrm{H}_{19} \mathrm{O}_{12}$ & 3.71 & 465.1033 & 465.1027 & 1.29 \\
\hline Quercetin-3-O-glucoside & $\mathrm{C}_{21} \mathrm{H}_{19} \mathrm{O}_{12}$ & 3.76 & 465.1033 & 465.1028 & 1.07 \\
\hline Kaempferol-3-O-rutinoside & $\mathrm{C}_{27} \mathrm{H}_{30} \mathrm{O}_{15}$ & 4.06 & 595.1662 & 595.1660 & 0.35 \\
\hline Quercetin-3-O-rutinoside & $\mathrm{C}_{27} \mathrm{H}_{30} \mathrm{O}_{16}$ & 3.76 & 611.1612 & 611.1609 & 0.49 \\
\hline
\end{tabular}

Identification confirmed using commercial standards. 


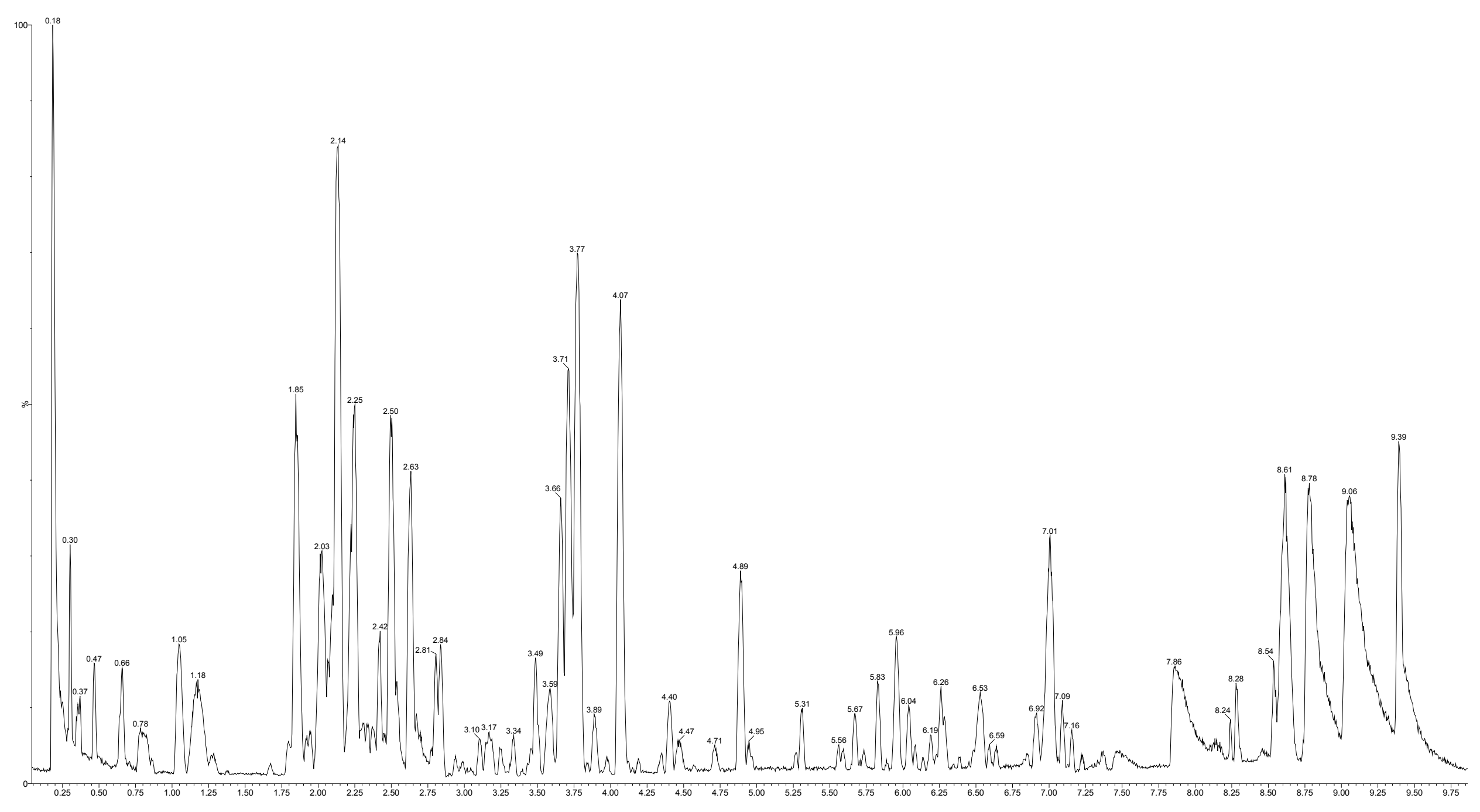

Figure 1. Total ion current chromatogram of aqueous extract of $S$. macrophylla leaves. 


\subsection{Effects of M1 Extract on Cell Viability of Cerebellar Primary Cultures}

Based on chromatographic profiles of the two extracts M1 and M2, obtained by LC-UV and antioxidant capacity data, it was possible to see that the results showed no significant differences. Thus, cytoprotective tests were conducted only with the extract obtained by decoction (M1), since this is the most widely used form for preparing medicinal plants in the region, and also produced the highest yield.

Our first experiments were designed to evaluate possible toxic effects resulting from the exposure of primary cerebellar mixed cultures to an aqueous M1 extract of mahogany leaves. Cultures were exposed to $\mathrm{M} 1$ extract for $24 \mathrm{~h}$ (acute) and $72 \mathrm{~h}$ (sub-chronic) at increasing concentrations ranging from $10 \mathrm{ng} / \mathrm{mL}$ and $200 \mu \mathrm{g} / \mathrm{mL}$. Our results showed that acute, but not sub-chronic exposure to M1 induced a concentration-dependent increase in cell viability, as measured by the colorimetric MTT assay (Figure 2).

As shown, sub-chronic exposure to the compound resulted in decrease in cell viability at the concentrations of 100 and $200 \mu \mathrm{g} / \mathrm{mL}$, compared to control values.

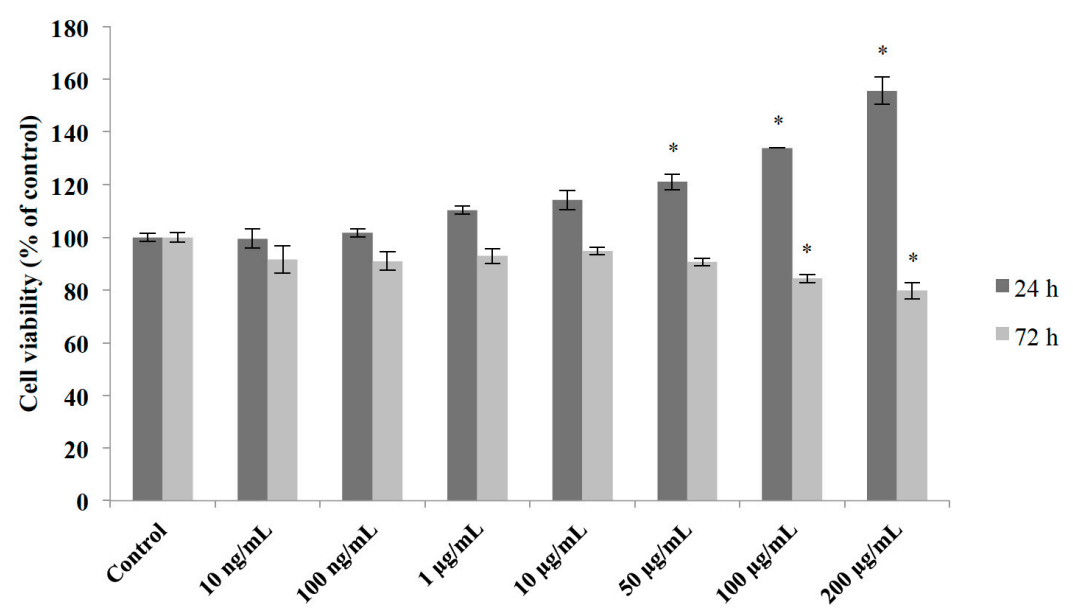

Figure 2. Effects of different dilutions of an aqueous extract of mahogany leaves (M1) on cell viability of cerebellar cultures. Cell viability was determined by MTT assay and is expressed as the percentage of untreated controls; mean + S.E.M. values of three-four independent experiments. $* p<0.01 v$ s. control group (one-way ANOVA followed by Tukey test).

\subsection{Cytoprotective Effect of an Aqueous Extract of Mahogany Leaves against Methyl Mercury-Induced Neurotoxicity}

Acute ( $24 \mathrm{~h}$ ) and sub-chronic ( $72 \mathrm{~h}$ ) exposure of primary cerebellar cultures to methyl mercury (MeHg) resulted in decreased cell viability time- and was dose-dependent (measured by MTT assay), under our experimental conditions (Figure 3).

In order to study the cytoprotective effects of Swietenia macrophylla, an extract rich in phenolic and flavonoids compound, and considering oxidative stress as an important effect of mercurial compounds on nervous tissue, we performed experiments where mixed cultures were exposed concomitantly to $\mathrm{MeHg}$ ( $6 \mu \mathrm{M}$ and $3 \mu \mathrm{M}$ for $24-$ and $72-\mathrm{h}$ exposure, respectively) and different concentrations of M1 aqueous extract $(10,50$ and $100 \mu \mathrm{g} / \mathrm{mL})$. 


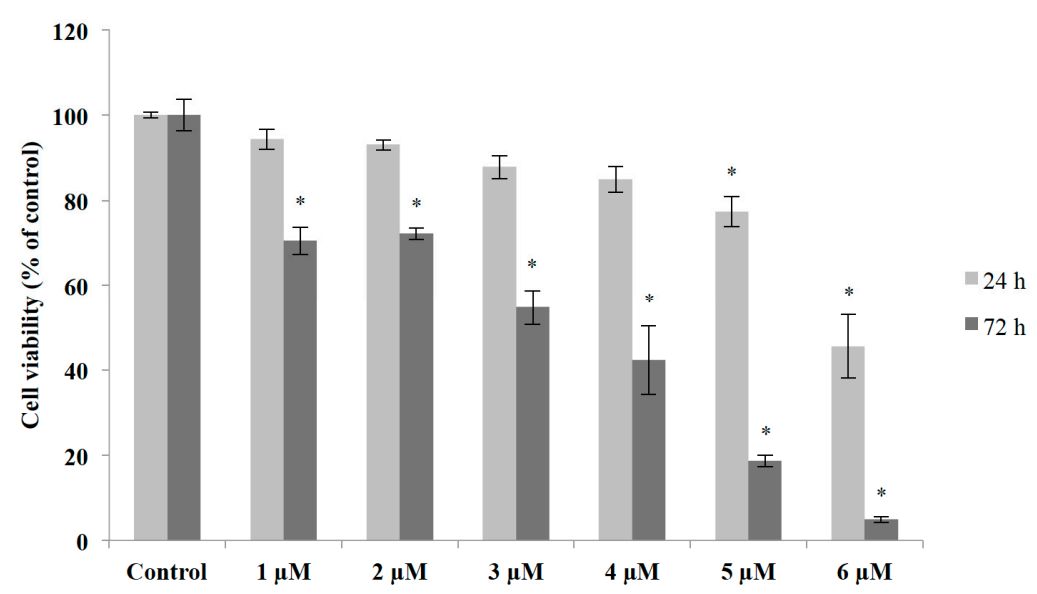

Figure 3. Effects of acute $(24 \mathrm{~h})$ and sub-chronic (72 h) exposure of methyl mercury in primary cerebellar cultures. Cell viability was determined by MTT assay and is expressed as the percentage of untreated controls; mean + S.E.M. values of three-four independent experiments. $* p<0.01 v s$. control group (one-way ANOVA followed by Tukey test).

As a result, concomitant addition of M1 extract $(10,50$ and $100 \mu \mathrm{g} / \mathrm{mL})$ to cultures exposed to $\mathrm{MeHg}$ $(6 \mu \mathrm{M})$ for $24 \mathrm{~h}$ resulted in no detectable effect on cell viability. On the other hand, simultaneous addition of the same concentrations of M1 extract to cultures exposed to $\mathrm{MeHg}(3 \mu \mathrm{M})$ for $72 \mathrm{~h}$ resulted in reversal or inhibition of the cytotoxic effects induced by MeHg in all concentrations tested. These results suggest that extract of Swietenia macrophylla provides significant protection to primary cerebellar cultures against damage caused by methyl mercury (Figure 4). Also, since this protective effect could only be observed for cultures exposed to $\mathrm{MeHg}$ for longer time $(72 \mathrm{~h}$ ), our data suggest that it could be related to an ability of M1 extract to promote gradual chelation against oxidative insult over time.

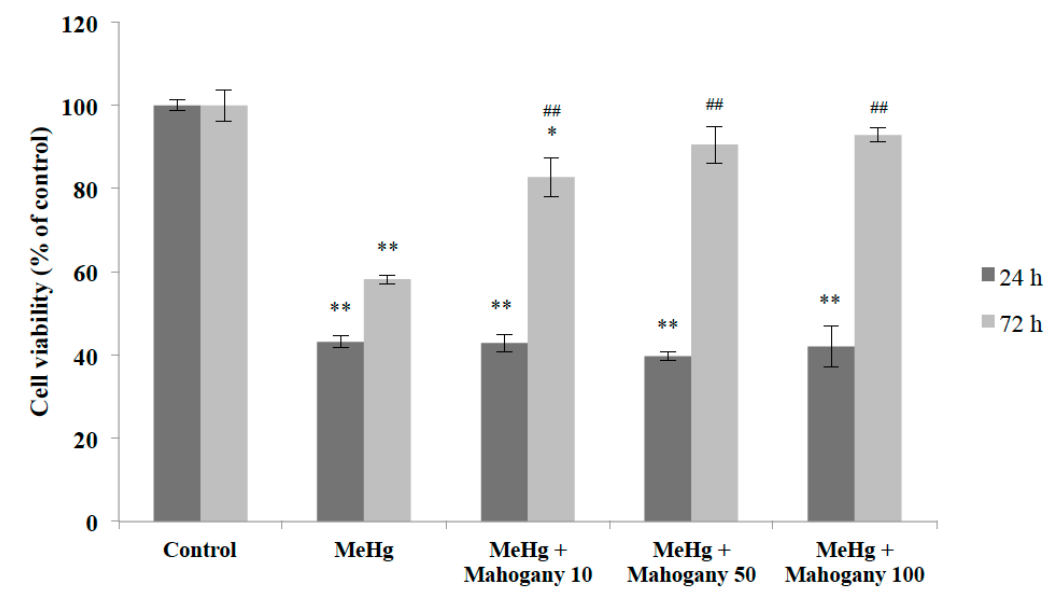

Figure 4. Evidence for cytoprotective effects of M1 aqueous extract on methyl mercury-induced cell loss. Cell viability was determined by MTT assay and is expressed as the percentage of untreated controls; mean + S.E.M. values of three-four independent experiments. $* p<0.05$ and $* * p<0.01$ vs. control group. ${ }^{* \#} p<0.01 v s$. MeHg group (one-way ANOVA followed by Tukey test). (MeHg: methyl mercury; Mahogany 10: aqueous extract of mahogany leaves $10 \mu \mathrm{g} / \mathrm{mL}$; Mahogany 50: aqueous extract of mahogany leaves $50 \mu \mathrm{g} / \mathrm{mL}$; Mahogany 100: aqueous extract of mahogany leaves $100 \mu \mathrm{g} / \mathrm{mL}$ ). 


\section{Experimental Section}

\subsection{Reagent and Standards}

Formic acid, methanol, MTT-tetrazole (3-(4,5-dimethylthiazol-2-yl)-2,5-diphenyltetrazolium bromide), potassium chloride, poly-L-lysine, glucose, HEPES and all standards were purchased from Sigma-Aldrich (Steinheim, Germany). The water was purified with a Direct-Q ${ }^{\circledR} 3$ system (18.2 Mohm resistivity, Merck KGaA, Darmstadt, Hessen, Germany). Additionally, Dulbecco Modified Eagle Medium (DMEM), fetal bovine serum, horse serum, penicillin/streptomycin antibiotics and trypsin/EDTA (Gibco-Invitrogen, Grand Island, NY, USA) were employed.

\subsection{Plant Material}

Swietenia macrophylla leaves were collected at Aurora do Pará, State of Pará, Brazil. The plant was identified by a botanic expert from the Botany Department, Universidade Federal Rural da Amazônia (Belém, State of Para, Brazil) and a voucher specimen (number 1320) was deposited at the Herbarium of this institution. The leaf samples were weighed $(3100 \mathrm{~g})$ and taken to the laboratory immediately after harvesting. The samples were dried at room temperature packed in paper bags for a period of 30 days. After this period, a new weighing of the dried leaves $(1642 \mathrm{~g})$ indicated a dehydration of $47.03 \%$.

\subsection{Preparation of S. Macrophylla Leaf Tea}

A sample of $100 \mathrm{~g}$ dried leaves was crushed and placed in $2.5 \mathrm{~L}$ of water and heated for 40 min to a temperature of $100{ }^{\circ} \mathrm{C}$ (extraction by decoction). Next, the warm mahogany tea was passed through a paper filter and the crude extract was lyophilized for $48 \mathrm{~h}$ to provide M1. The mass obtained was $17.09 \mathrm{~g}$ with a yield of $17.1 \%$. The same mass of dried leaves was crushed and placed into $2.5 \mathrm{~L}$ of boiling water at a temperature of $100{ }^{\circ} \mathrm{C}$ for $5 \mathrm{~min}$ (extraction by infusion). The warm mahogany tea was then passed through a paper filter and the crude extract was lyophilized for $48 \mathrm{~h}$ to provide M2. The mass obtained was $8.82 \mathrm{~g}$ with a yield of $8.8 \%$. The LC-MS sample was prepared using a $13 \mathrm{~mm}$ film $\times 0.2 \mu \mathrm{m}$ PTFE 13-2 Iso-Disc ${ }^{\text {TM }}$ membrane filter (Supelco-Sigma-Aldrich, St. Lois, MO, USA).

\subsection{TEAC Assay}

The antioxidant capacity was measured using the TEAC assay, with the radical cation ABTS ${ }^{+\bullet}$ (Sigma, St. Louis, MO, USA) and $\mathrm{K}_{2} \mathrm{~S}_{2} \mathrm{O}_{8}$ (Sigma) as the oxidant agent, as adapted by Silva et al. [15] from the procedure proposed by Re et al. [16] to be used with a microplate reader. The TEAC value represents the antioxidant reactivity relative to a standard of $1.0 \mathrm{mmol} / \mathrm{L}$ Trolox, a water-soluble synthetic derivative of vitamin E. In this study, the TEAC value was expressed as mmol of Trolox equivalent (TE) per g of dry extract or dry fraction. All analyses were done in triplicate.

\subsection{Folin-Ciocalteau Assay}

The antioxidant capacity was measured by the Folin-Ciocalteau colorimetric method [20,21]. Measurements were carried out by reaction of the Folin-Ciocalteau reagent $(1 \mathrm{~N})$ with $\mathrm{Na}_{2} \mathrm{CO}_{3}$ diluted in water $(75 \mathrm{~g} / \mathrm{L})$ and samples diluted in water, during $30 \mathrm{~min}$ and measured at $735 \mathrm{~nm}$. The assay were 
developed in triplicate and calculations based on a calibration curve obtained with gallic acid. The results were expressed as milligram of gallic acid equivalents (GAE) per g of dry extract or dry fraction.

\subsection{Analytical LC-MS/MS}

LC-MS analysis was performed on a XEVO G2-SQ-TOF mass spectrometer (Waters Corp., Milford, MA, USA) equipped with a lockspray source where an internal reference compound (leucine-enkephalin) was introduced simultaneously with the analyte for accurate mass measurements. Compounds were separated in a HSS C18 column (Waters Corp.; $50 \mathrm{~mm} ; 2.1 \mathrm{~mm} ; 1.8 \mu \mathrm{m}$ particle size) using $0.1 \%$ aqueous formic acid (solvent $\mathrm{A}$ ) and $0.1 \%$ formic acid in methanol (solvent $\mathrm{B}$ ). Column temperature was maintained at $40^{\circ} \mathrm{C}$.

Gradient elution was performed with $0.1 \%$ formic acid in ultra-pure water (solvent $\mathrm{A}$ ) and methanol (solvent B), delivered at a flow rate of $0.5 \mathrm{~mL} / \mathrm{min}$ as follows: $2 \% \mathrm{~B}$ in $1 \mathrm{~min}, 2 \%-95 \% \mathrm{~B}$ in $8 \mathrm{~min}, 95 \%$ $\mathrm{B}$ during 1 additional minute. The gradient elution was followed by a $5 \mathrm{~min}$ post-run at initial conditions for equilibration of the column. The injection volume for the extract was $5 \mu \mathrm{L}$. The analysis was done in ESI positive ion mode. A confirmation method was also developed using a $\mathrm{MS}^{\mathrm{e}}$ method to confirm overlapped peaks in the extract chromatogram. For this, the same MS source parameters and UPLC conditions were applied.

Electrospray mass spectra data were recorded in a positive ionization mode for a mass range from $\mathrm{m} / \mathrm{z} 50$ to 1000 with a scan time of $0.1 \mathrm{~s}$. The source temperature was set to $150^{\circ} \mathrm{C}$ with a cone gas flow of $20 \mathrm{~L} / \mathrm{h}$. The desolvation gas flow was set to $600 \mathrm{~L} / \mathrm{h}$ at a temperature of $250{ }^{\circ} \mathrm{C}$. The capillary was set at $3.5 \mathrm{kV}$ with cone voltage at $20 \mathrm{~V}$. Collision-induced fragmentation (CID) of the analytes was achieved using 20-40 V of energy with argon as the collision gas. MassLynx software (Waters) was used for system control and data acquisition.

\subsection{Cell Culture}

Primary cerebellar cultures were obtained from 5-7 days-old Wistar rats. The Animal Care and Use Committee of the University Federal of Pará approved all of the animal protocols used. Cultures were prepared as described previously to Ahlemeyer and Baumgart-Vogt [22], with minor modifications. Briefly, brain was rapidly removed and dissected in a petri dish with sterile dissection medium (160 mM $\mathrm{NaCl} ; 5.3 \mathrm{mM} \mathrm{KCl} ; 0.44 \mathrm{mM} \mathrm{KH}_{2} \mathrm{PO}_{4} ; 0.33 \mathrm{mM} \mathrm{Na}_{2} \mathrm{HPO}_{4} ; 4 \mathrm{mM} \mathrm{NaHCO}_{3} ; 5.5 \mathrm{mM}$ glucose; antibiotics and antifungal). The brain meninges were carefully removed and the cerebellum was incubated for $15 \mathrm{~min}$ at $37^{\circ} \mathrm{C}$ in a trypsin-EDTA $0.05 \%$ solution for enzymatic digestion. The digested tissue was transferred to culture medium DMEM containing $10 \%$ fetal bovine serum, $10 \%$ horse serum, $25 \mathrm{mM} \mathrm{KCl}$, penicillin-streptomycin $10,000 \mathrm{U} / \mathrm{mL}$, and gently mechanically disrupted with a Pasteur pipette. After brief decantation, cells in suspension were seeded in multi-well plates previously treated with poly-L-lysine in DMEM supplemented with 10\% FBS, 10\% HS, $25 \mathrm{mM} \mathrm{KCl}$ and penicillin-streptomycin, and maintained at $37{ }^{\circ} \mathrm{C}$ with $5 \% \mathrm{CO}_{2}$ in a humidified atmosphere for 8 days, at which point cultures were confluent and the experiments were performed. 


\subsection{Methyl Mercury-Induced Oxidative Damage in Primary Cerebellar Cultures}

Treatment consisted in the addition of methyl mercury dissolved in water to the primary cerebellar cultures, for two different periods of exposure (acute, $24 \mathrm{~h}$ and sub-chronic, $72 \mathrm{~h}$ ) in concentration ranging from $1 \mu \mathrm{M}$ to $6 \mu \mathrm{M}$.

\subsection{Treatment with Aqueous Extract of Swietenia Macrophylla to Neuroprotective Assays}

The Swietenia macrophylla extract was submitted to a serial dilution. To check possible toxic effects, primary cerebellar cultures were treated with the extract in concentrations ranging from $10 \mathrm{ng} / \mathrm{mL}$ to $200 \mu \mathrm{g} / \mathrm{mL}$ (final concentration in culture medium). Cell viability was examined by MTT assay. After that, three concentrations (non-toxic) were chosen for the evaluation of the possible neuroprotective effect.

\subsection{Analysis of Cell Viability}

Cell viability was measured by the MTT (3-(4,5-dimethylthiazol-2-yl)-2,5-diphenyltetrazolium bromide) method. Each experimental condition was performed in triplicate wells ( $n=3$ to 4 independent experiments). The control-wells were considered as having $100 \%$ viability and then compared with treated-wells in that group. Data were described as standard error mean ( \pm S.E.M.).

\subsection{Statistical Analysis}

Results are expressed as mean values ( \pm S.E.M.). The statistical evaluation of the data was performed by One-way analysis of variance (ANOVA) followed by Tukey post hoc test. $p<0.05$ was accepted as statistically significant.

\section{Conclusions}

In this study, tea from mahogany leaves showed promise as an antioxidant source, using two antioxidant reference methods. In this sample, 27 polyphenols have been identified, among them, nine phenolic acids and 18 flavonoids, particularly 3-O-flavonols. Additionally, the LC-HRMS system provided unequivocal identification of these phenolic compounds with high mass accuracy. Such compounds are usually considered responsible for antioxidant capacity. Our results also showed that concomitant exposure of the same cultures to $\mathrm{MeHg}$ and aqueous extract resulted in significant increase in cell viability in all doses used, suggesting that this extract, provides significant cytoprotection in the $\mathrm{MeHg}$-induced in vitro neurotoxicity and above all, that mahogany leaves, a waste material from the timber industry, could be a useful source of bioactive compounds, adding value to this species.

\section{Acknowledgments}

The authors are grateful to Conselho Nacional de Desenvolvimento Científico e Tecnológico (CNPq), Fundação de Amparo à Pesquisa do Estado do Pará (FAPESPA), Coordenação de Aperfeiçoamento de Pessoal de Ensino Superior (CAPES) and Pró-Reitoria de Pesquisa e Pós-Graduação (PROPESP) for financial support. 


\section{Author Contributions}

The contributions of the respective authors are as follows: P.S. and S.P performed phytochemical studies under orientation of M.S. D.L. performed neuroprotective experiments under orientation of E.C. and E.Y. which also designed the protocol of the experiments and revised the neuroprotective data. C.S. and M.S. performed LC-MS experiments and wrote the manuscript. J.S. performed antioxidant assays and M.A. revised phytochemical data.

\section{Conflicts of Interest}

The authors declare no conflict of interest.

\section{References}

1. Rahman, T.; Hosen, I.; Islam, M.M.T.; Shekhar, H.U. Oxidative stress and human health. Adv. Biosci. Biotechnol. 2012, 3, 997-1019.

2. Surmeier, D.J.; Guzman, J.N. The Origins of Oxidant Stress in Parkinson's Disease and Therapeutic Strategies. Antioxid. Redox Signal. 2011, 7, 1289-1301.

3. Uttara, B.; Singh, A.V.; Zamboni, P.; Mahajan, R.T. Oxidative Stress and Neurodegenerative Diseases: A Review of Upstream and Downstream Antioxidant Therapeutic Options. Curr. Neuropharmacol. 2009, 7, 65-74.

4. Farina, M.; Avila, D.S.; da Rocha, J.B.; Aschner, M. Metals, Oxidative Stress and Neurodegeneration: A focus on Iron, Manganese and Mercury. Neurochem. Int. 2013, 5, 575-594.

5. Dai, J.; Mumper, R.J. Plant Phenolics: Extraction, Analysis and Their Antioxidant and Anticancer Properties. Molecules 2010, 15, 7313-7352.

6. Mira, A.; Yamashita, S.; Katakura, Y.; Shimizu, K. In Vitro Neuroprotective Activities of Compounds from Angelica shikokiana Makino. Molecules 2015, 20, 4813-4832.

7. Brown, N.; Jennings, S.; Clements, T. The ecology, silviculture and biogeography of mahogany (Swietenia macrophylla): A critical review of the evidence. Perspect. Plant Ecol. Evol. Syst. 2003, 6, 37-49.

8. Lemes, M.R.; Gribel, R.; Proctor, J.; Grattapaglia, D. Population genetic structure of mahogany (Swietenia macrophylla King, Meliaceae) across the Brazilian Amazon, based on variations at microsatellite loci: Implications for conservation. Mol. Ecol. 2003, 12, 2875-2883.

9. Falah, S.; Suzuki, T.; Katayama, T. Chemical constituents from Swietenia macrophylla bark and their antioxidant activity. Pak. J. Biol. Sci. 2008, 11, 2007-2012.

10. Da Silva, M.N.; Arruda, M.S.P.; Castro, K.C.F.; da Silva, M.F.; Das, G.F.; Fernandes, J.B.; Vieira, P.C. Limonoids of the phragmalin type from Swietenia macrophylla and their chemotaxonomic significance. J. Nat. Prod. 2008, 71, 1983-1987.

11. Mootoo, B.S.; Ali, A.; Motilal, R.; Pingal, R.; Ramlal, A.; Khan, A. Limonoids from Swietenia macrophylla and S. aubrevilleana. J. Nat. Prod. 1999, 62, 1514-1517.

12. Chen, J.J.; Huang, S.S.; Liao, C.H.; Wei, D.C.; Sung, P.J.; Wang, T.C.; Cheng, M.J. A new phragmalin-type limonoid and anti-inflammatory constituents from the fruits of Swietenia macrophylla. Food Chem. 2010, 120, 379-384. 
13. Tsao, R.; Yang, R. Optimization of a new mobile phase to know the complex and real polyphenolic composition: Towards a total phenolic index using high-performance liquid chromatography. J. Chromatogr. A 2003, 1, 29-40.

14. Sakakibara, H.; Honda, Y.; Nakagawa, S.; Ashida, H.; Kanazawa, K. Simultaneous Determination of All Polyphenols in Vegetables, Fruits, and Teas. J. Agric. Food Chem. 2003, 3, 571-581.

15. Silva, E.M.; Souza, J.N.S.; Rogez, H.; Rees, J.F.; Larondelle, Y. Antioxidant activities and polyphenolic contents of fifteen selected plant species from the Amazonian region. Food Chem. 2007, 101, 1012-1018.

16. Re, R.; Pelligrini, N.; Proteggente, A.; Pannala, A.; Yang, M.; Rice-Evans, C.A. Antioxidant activity applying an improved ABTS radical cation decolorization assay. Free Radic. Biol. Med. 1999, 26, 1231-1237.

17. Arun, R.; Sravya, R.B.; Roja, C. A review on standardisation of herbal formulation. Inter. J. Phytother. 2012, 2, 74-88.

18. Vlase, L.; Parvu, M.; Parvu, E.A.; Toiu, A. Chemical Constituents of Three Allium Species from Romania. Molecules 2013, 18, 114-127.

19. Almajano, M.P.; Carbo, R.; Jiménez, J.A.L.; Gordon, M.H. Antioxidant and antimicrobial activities of tea infusions. Food Chem. 2008, 108, 55-63.

20. Singleton, V.L.; Rossi, J.A. Colorimetry of Total Phenolics with Phosphomolybdic-Phosphotungstic Acid Reagents. Am. J. Enol. Viticult. 1965, 16, 144-158.

21. Singleton, V.L.; Othofer, R.; Lamuela-Raventos, R.M. Analysis of total phenols and other oxidation substrates and antioxidants by means of Folin-Ciocalteu reagent. Methods Enzymol. 1999, 299, $152-178$.

22. Ahlemeyer, B.; Baumgart-Vogt, E. Optimized protocols for the simultaneous preparation of primary neuronal cultures of the neocortex, hippocampus and cerebellum from individual newborn (P0.5) C57B1/6J mice. J. Neurosci. Methods 2005, 149, 110-120.

(C) 2015 by the authors; licensee MDPI, Basel, Switzerland. This article is an open access article distributed under the terms and conditions of the Creative Commons Attribution license (http://creativecommons.org/licenses/by/4.0/). 